Proceedings

\title{
Dose-Dependent Cytotoxicity of the Origanum vulgare and Carvacrol on Triple Negative Breast Cancer Cell Line
}

\author{
Brian Rojo-Ruvalcaba ${ }^{1}$, Teresa García-Cobián ${ }^{2}$, Sara Pascoe-González ${ }^{2}$, Tannia Campos- \\ Bayardo 2, Luz Guzmán-García 1, María Gil-Gálvez 1, Zyanya Escobar-Millán 1, Eduardo Huerta- \\ García $^{1}$ and Trinidad García-Iglesias ${ }^{1, *}$ \\ 1 Laboratorio de Inmunología \\ 2 Instituto de Terapeutica Experimental y Clinica, Dpto. Fisiologia del Centro Universitario de Ciencias de la \\ Salud, Universidad de Guadalajara, Sierra Mojada 950, Col. Independencia, P.C. 44340 Guadalajara, Jalisco, \\ Mexico \\ * Correspondence: trini.iglesias@gmail.com; Tel.: +523-315-294-449
}

Published: 30 October 2020

\begin{abstract}
Uncontrolled proliferation and death resistance are two hallmarks of cancer cells [1]. Breast cancer (BC) has the highest incidence and mortality in women worldwide and national, subtype triple negative (TN) is the most aggressive because it is not susceptible to conventional therapy [2-4]. Since 2004 World Health Organization (WHO) approved use of alternative treatments as adjuvants based on evidence of its benefits, since then have been studied different natural alternatives to treat cancer, here stand out the Origanum vulgare (Ov) and carvacrol (Crv), one of its main compounds, however, cytotoxic potential of these products has not been studied in this subtype of BC [5-7]. The objective of this study was evaluate the cytotoxic effect of the Ov and Crv on TN BC cell line (HCC-70). Lethal dose 50 was determined on control cell line HaCaT through MTT assays with $\mathrm{Ov}$ and $\mathrm{Crv}$ stimulus in different doses and concentrations, the found dose was used on HCC-70 cell line. The results were evaluated by ANOVA, finding that Ov reduce the proliferation by $94.05 \% \pm 0.11(p<0.001)$ and Crv by $93.43 \% \pm 0.21(p<0.001)$ compared to untreated cells. This suggests that both the $O v$ and Crv presents a powerful cytotoxic effect against HCC-70 cell line and are promising optional that should continue studying.
\end{abstract}

Keywords: breast cancer; triple negative; cytotoxicity; Origanum vulgare; carvacrol; adjuvant treatment

\section{Introduction}

Cancer is defined by WHO as a cellular uncontrolled process of growth and dissemination that can appear anywhere on the body [8]. BC is the one that originates in breast tissues, and it can be spread through blood and lymphatic vessels $[9,10]$.

Perou in 2000 purposed a molecular classification of breast cancer, identifying 4 subtypes based on expression or absence of a series of receptors necessary for the efficacy of conventional treatment; Luminal A: It is the most common and least aggressive (positive for progesterone receptor and estrogen receptor), Luminal B: It has a higher proliferation index and a least response to conventional treatment (positive for progesterone receptor, estrogen receptor and Her2/neu), HER2/neu: It is the least common subtype and highly aggressive due to increased expression of genes related with cellular proliferation (Her2/neu positive), by last the basal subtype (TN): does not express any of the receptors named above due to this subtype is not susceptible to conventional treatments $[4,11,12]$.

Regarding epidemiology, worldwide, cancer is a great public health problem. The WHO suggested the 10,000,000 cases of cancer per year worldwide and 6,000,000 deaths because of cancer 
every year. It has also announced that cancer population will increase up to 20 million cases/year in this year [13]. Talking about breast cancer, the last report of Global Cancer Observatory shows that worldwide incidence of BC is 2,088,849 cases, and in 2018 was recorded a total of 626,679 deaths because this type of cancer. Based on these data, $\mathrm{BC}$ is the leading in incidence and mortality in women worldwide [3]. Furthermore, cases diagnosed in late stages decrease the survival probabilities due to conventional treatment low effectiveness in cancer advanced stages. This diagnosed happens mainly in underdeveloped and developing countries where the costs for the patient can exceed their income [14,15].

Natural products have been used throughout human history in traditional medicine, and in later years, it became evident that the development of novel treatments based on bioactive natural products would be defining the future of global healthcare because that natural products lead the way to the discovery of new therapeutic compounds for the treatment of human diseases [16-19]. Further, since $2004 \mathrm{WHO}$ approved use of alternative treatments as adjuvants based on evidence of its benefits, showing a clear revival of interest to herbal medicine and development of novel phytochemical anticancer agents have gained significant recognition in the field of cancer therapy $[5,20]$. In this field, medicinal plants represent one of the main sources of active compounds with antiproliferative activities because it has been shown to be an excellent source of new drugs that in addition to its effectiveness, does not have large side-effect consequences compared to synthetic drugs $[7,20,21]$.

The infusions are products with various biological properties, and for centuries they have been used in traditional medicine, in the last decades with the resurgence of interest in traditional medicine the herbalism has acquired great interest around the world due to its anticancer activity and the possible use as an adjuvant treatment of certain plants [22,23]. Here highlights the Ov commonly called oregano, it is a perennial herbaceous plant (that live more than two years), aromatic of the genus Origanum that belongs to the Lamiaceae family, in addition to its uses in the kitchen it is used in home remedies and as complementary medicine. Around 64 compounds have been described in this plant, where it has been found that Crv is the one found in the highest proportion, this is a highly bioactive monoterpenoid phenol [6,22,24-29]. Both oregano and Crv have been studied for their cytotoxic potential in different subtypes of breast cancer, however, cytotoxic potential of these products has not been studied in this subtype of breast cancer.

The objective of this study was evaluate the cytotoxic effect of the $O v$ and Crv on TN BC cell line (HCC-70), and compare if all the compounds present in the $O v$ infusion can exert a synergistic effect that enhances the cytotoxic activity or if Crv has the highest cytotoxic activity against this type of breast cancer.

\section{Methods}

\subsection{Chemicals}

Dulbecco's Modified Eagle Medium (DMEM) Roswell Park Memorial Institute (RPMI-1640), dimethyl sulfoxide (DMSO), 3-(4,5-dimethylthiazol-2-yl)-2,5-diphenyltetrazolium bromide (MTT), Phosphate Buffered Saline (PBS), and Crv ( $\geq 98 \%$ purity) were purchased from Sigma Aldrich. Fetal Bovine Serum (FBS), Extraction Buffer (EB), Tripan Blue (TB), and Antibiotic-Antimycotic (AA) were purchased from Thermo Fischer Scientific ${ }^{\mathrm{TM}}$. All solvents and chemicals were of an analytical grade.

\subsection{Plant Material}

The $O v$ used in this study is an endemic species from the region of Guadalajara, Mexico.

\subsubsection{Preparation of Ov Infusion}

We use $250 \mathrm{mg}$ of dry leaves were ground to a fine powder using a porcelain mortar. The powder was suspended in $10 \mathrm{~mL}$ of sterile boiling water for $5 \mathrm{~min}$. The resulting infusion was filtered with a $0.22 \mu \mathrm{M}$ sterile filter into a laminar flow hood (Figure 1A). 


\subsubsection{Preparation of Crv Solution}

$20 \mu \mathrm{L}$ of Crv were mixed with $80 \mu \mathrm{L}$ of DMSO (allow Crv to solubilize in an aqueous medium) and $900 \mu \mathrm{L}$ of culture medium to obtain a $2 \%$ solution. Then the solution was mixed for ten second in a Vortex (Figure 1B).

\subsubsection{Cell Lines and Cell Cultures}

The cells lines were purchased from ATCC. Human keratinocyte transformed and immortalized $\mathrm{HaCaT}$ cells were maintained in RPMI supplemented with $10 \%$ of SFB and $1 \%$ of AA. This cell line was used as control for this study. Human TN BC cells HCC-70 were maintained in DMEM supplemented with $10 \%$ of SFB and $1 \%$ of AA. The cell cultures were kept in an incubator under physiological conditions $\left(37^{\circ} \mathrm{C}, 95 \%\right.$ humidity and $5 \% \mathrm{CO} 2$ saturation). All cell were cultures and received the necessary culture media changes until reach a confluence of $100 \%$. Then cells were recovered by trypsinization technique (1-2 $\mathrm{mL}$ of trypsin in the culture flask without culture medium and incubate for $5 \mathrm{~min}$ ), trypsin was inactivated with culture medium and the cells were centrifuged (1500 RPM for $5 \mathrm{~min}$ ) to obtain a pellet. This was resuspended with $1 \mathrm{~mL}$ of culture medium.

\subsubsection{Cell Viability Assay and Cell Count}

The cell viability was evaluated through TB assay, and the cell count was performed with a Neubauer chamber. TB assay is based on the principle that live cells possess intact cell membranes that exclude certain dyes, such as trypan blue. $1 \mu \mathrm{L}$ of cells was mixed with $9 \mu \mathrm{L}$ of TB to create a 1:10 dilution, and this was placed in the Neubauer chamber. Viable cells were counted when the chamber was analyzed in the microscope.

\subsubsection{Cytotoxicity Test (MTT Test)}

The MTT assay [30] is based on the capability of viable cells to convert this yellow water-soluble tetrazolium salt into insoluble purple formazan crystals by cleavage of the tetrazolium ring by dehydrogenase enzymes. This water insoluble product can be solubilized using organic solvents and the resulting colored solutions are spectrophotometrically measured, getting an absorbance directly proportional to the percentage of viable cells. Cells were seeded in triplicate in 96-well plates at a density of $1 \times 10^{4}$ cells/well. After $24 \mathrm{~h}$ of culture, cells were treated with or without increasing concentrations of $\mathrm{Ov}$ infusion and $\mathrm{Crv}$ solution (culture medium was used for untreated groups) and incubated for $24 \mathrm{~h}$. Then MTT ( $5 \mathrm{mg} / 1 \mathrm{~mL}$ PBS) was added to the cells, incubating for $18-24 \mathrm{~h}$. The formazan crystals were dissolved with EB. The absorbance was measured at a wavelength of $570 \mathrm{~nm}$. The untreated cells were considered $100 \%$ viable. The concentration that reduces the cell viability to half is observed as IC50, is a measure of the effectiveness of a substance in inhibiting cell multiplication. The lethal dose 50 found both the $\mathrm{Ov}$ infusion and the $\mathrm{Crv}$ in the control cell line was used in TN BC cells (HCC-70). The experiments were carried out in triplicate at independent times.

\subsection{Statistical Analysis}

Results were expressed as means \pm SD. An ANOVA was performed using IBM SPSS Statistics 24 , and a $p$ value of $<0.05$ was considered statistically significant. 


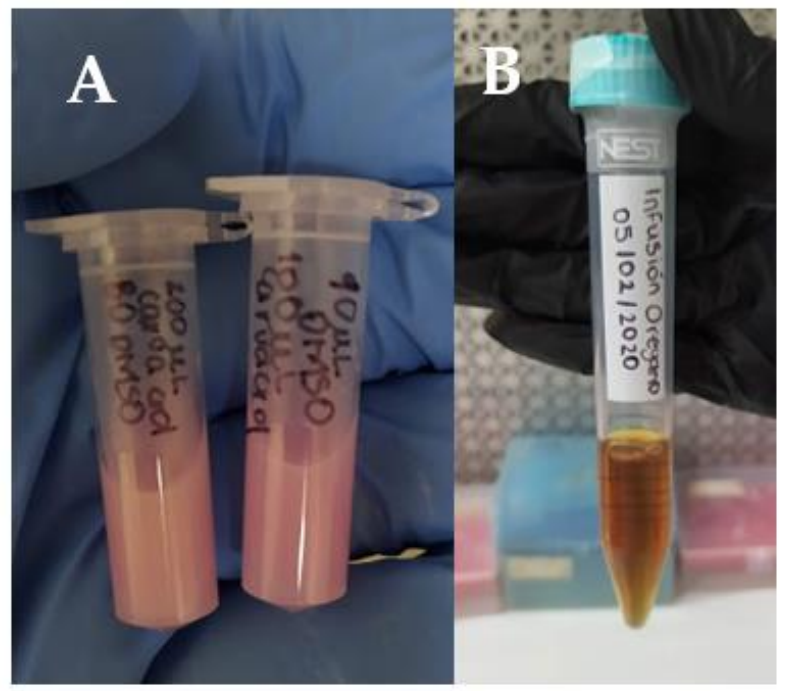

Figure 1. Photographs of the Crv solution (A) and $O v$ infusion (B). Both stimuli were prepared the same day that were used.

\section{Results and Discussion}

\subsection{Cell Viability}

Figure 2A,B shows the difference in the proliferation of the HaCaT cell line culture. Cells were recovered successfully, on the Figure 2C a culture with $90 \%$ confluence can be seen after the trypsinization process. In the cell viability tests percentages exceeding $80 \%$ were found indicating the good state of the cell culture. An example of this assay in the HCC-70 cell line is shown in the Figure 2D.

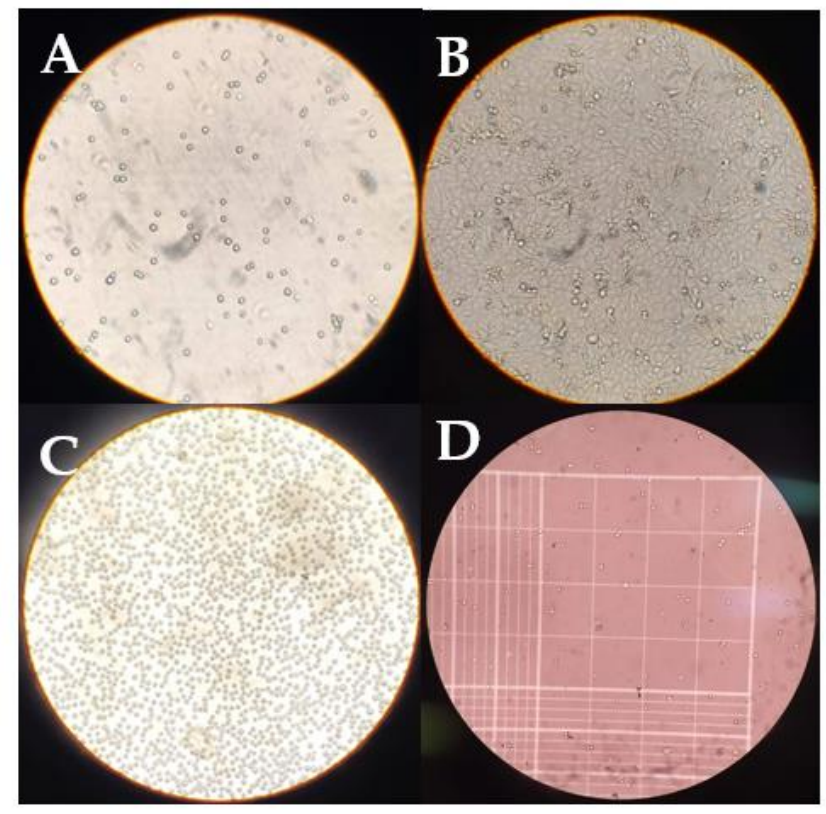

Figure 2. (A) HaCaT cell culture at day 1. (B) HaCaT cell culture upon reaching $>90 \%$ confluence, in addition to cell proliferation it is appreciated how the cells are adhered to the base of the culture flask. (C) HaCaT cell culture after the recovery process by trypsinization, a more rounded shape is observed in cultured cells after the adherent cell recovery process. (D) Viable cells appear white and those that are not are stained blue, practically no non-viable cells can be seen. Photographs of cell cultures were taken by observing them under an inverted microscope while the photograph of Neubauer's chamber was taken by observing it under a microscope. 


\subsection{Cytotoxicity}

In the first trial, a dose response curve was performed in the HaCaT cell line, exposing it to 4 ascending doses of $2 \% \operatorname{Crv}(20 \mu \mathrm{L}, 40 \mu \mathrm{L}, 60 \mu \mathrm{L}$ and $80 \mu \mathrm{L})$ to standardize the IC50. The results showed that the proliferation indices decreased in a dose-dependent manner with significant reductions in proliferation index values from the second dose wich had a concentration of $0.028 \mathrm{M}$ $(33.06 \% \pm 5.35)$, and it was further potentiated in the third $(10.28 \% \pm 1.29)$ and fourth doses $(9.95 \% \pm$ 2.06) that had a concentration of $0.042 \mathrm{M}$ and $0.056 \mathrm{M}$ respectively (Figure 3).

After that, the control cell line $\mathrm{HaCaT}$ was exposed to 2 ascending doses of the Ov infusion (20 $\mu \mathrm{L}$ and $40 \mu \mathrm{L}$ ) at a concentration of $250 \mathrm{~g} / 10 \mathrm{~mL}$, finding that the proliferation indices decreased to $18.62 \% \pm 1.43$ with the first dose and $12.75 \% \pm 1.41$ with the second (Figure 4 ).

Once the lethal dose 50 for the $\mathrm{Ov}$ infusion and $\mathrm{Crv}$ had been standardized, the cytotoxicity test was carried out in the TN BC cell line (HCC-70) which was exposed to dose 2 of Crv $(0.028 \mathrm{M})$ and dose 2 of the $O v$ infusion $(40 \mu \mathrm{L})$. The results showed that the $O v$ infusion reduces the proliferation index of these cells to $5.95 \% \pm 0.11(p<0.0001)$ while the Crv reduces it to $6.57 \pm 0.21(p<0.001)$ (Figure $5)$.

Similar results on the cytotoxicity of carvacrol against different cancer cell lines have been reported., for example, Fahad Khan et al. in 2017 found in their study that carvacrol doses of 25, 50, 100,250 and $500 \mu \mathrm{M}$ reduced the in vitro cell viability of prostate cancer cells (DU145) by $79.42 \%$, $59.48 \%, 46.85 \%, 15.63 \%$ and $11.70 \%$ respectively, this after a 24 -hour stimulus exposure. The lethal dose 50 for this cell line was found with a concentration of approximately $84.39 \mu \mathrm{M}$ [31]. Moreover, Hazem Elshafie et al. in 2017 analyzed the in vitro cytotoxic potential of the compounds present in a higher proportion in oregano against hepatocarcinoma cells (HepG2), reporting that carvacrol was the compound with the greatest potential to inhibit the proliferation of this cell line, the lethal dose 50 found in this study was $48 \mathrm{mg} / \mathrm{L}$ [22]. These results, among some other studies that have been carried out on this compound and its properties against cancer cells are consistent with the fact that carvacrol has a potent in vitro cytotoxic effect against different cancer cell lines like MDA-231 and MCF-7 [31-37]. However, the present study provides the first evidence on the effectiveness of this compound against TN BC cells (HCC-70), demonstrating the potency of its cytotoxic activity against aggressive subtypes of BC.

Talking about $O v$, studies of this plant have been carried out with different cancer cell lines, as in colon cancer (HT-29), melanoma (A375) and hepatocarcinoma (HepG2), where a significant reduction in cell viability has been found in a dose-dependent manner [22,38,39]. Specifically, about breast cancer, Hanane Makrane et al. in 2018 reported that MDA-MB-231 BC cells were more susceptible to the cytotoxic effect of Ov compared to colon cancer cells (HT-29), as it was observed that cell viability decreased drastically in BC cells as the dose of $O v$ increased, finding the IC50 at a dose of $87.09 \mu \mathrm{g} / \mathrm{mL}$ [39].

Moreover, Katerina Spyridopoulou et al. reported that $O v$ showed anti-proliferative activity against MCF-7 (luminal A) BC cells in a dose-dependent manner, in their study, different cancer cell lines were subjected to $\mathrm{Ov}$ and the $\mathrm{BC}$ cell line was the third in which a stronger anti-proliferative effect was observed, with a lethal dose 50 of $10.0 \pm 1.7 \mu \mathrm{g} / \mathrm{mL}$ [38]. Although there are few studies on the cytotoxicity of $O v$ in cancer cell lines the most relevant ones agree that it has a powerful cytotoxic potential.Specifically, in TN-BC cells, the effect of the infusion of Ov or Crv has not been studied, since most of the studies that have been published on the subject are in cell lines such as MCF-7 (luminal A) and MDA-MB-231 (breast adenocarcinoma)[22,23,31,33,38-42].

However, analyzing the results of studies on the cytotoxic effect of $\mathrm{Ov}$ and $\mathrm{Crv}$ on cancer cell lines, can be inferred that both have a powerful cytotoxic activity against these cells, some studies have even carried out tests in in vivo models with $\mathrm{Ov}$, finding that it has the ability to significantly slow tumor growth of colon carcinoma in mice, among other effects [38]. Based on all the above and on the results of the present study, we can say that both the infusion of $O v$ and Crv show a powerful cytotoxic effect against TN BC cells (HCC-70), and these results represent the precedent for further studies to continue analyzing the efficacy of this effect because the results are promising so that in 
the near future, alternatives of adjuvant treatment can be offered in the management of aggressive types of BC.

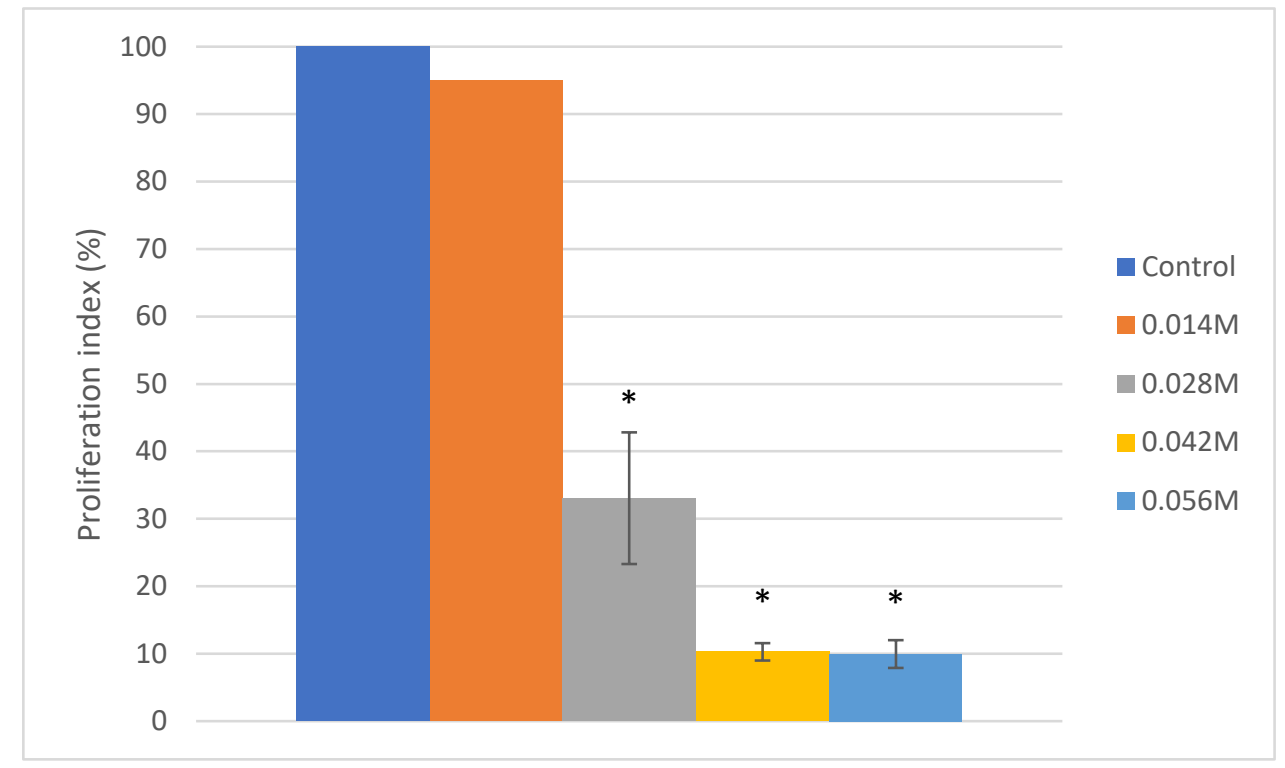

Figure 3. Graphic representation of the proliferation index of HaCaT cells exposed to Crv. Significance ${ }^{*} p<0.0001$. Data are expressed as mean of three replicates.

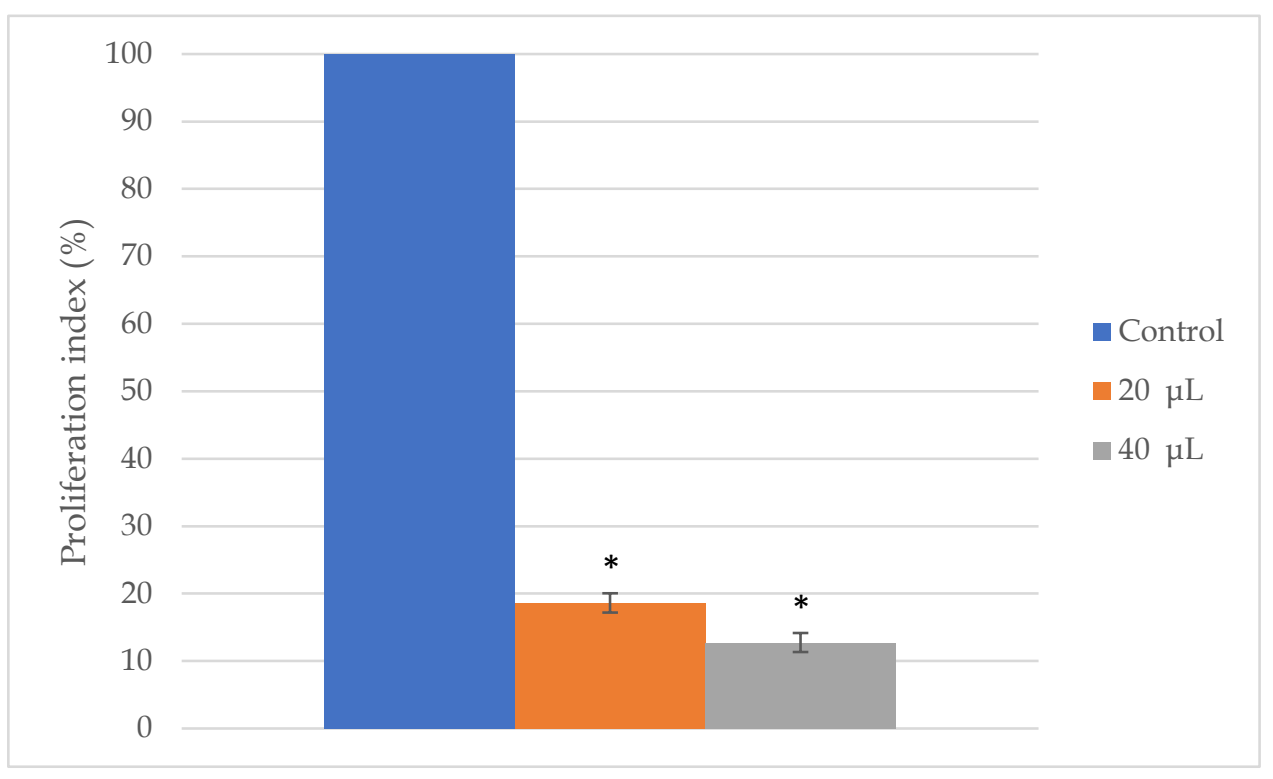

Figure 4. Graphic representation of the proliferation index of HaCaT cells exposed to the Ov infusion. Significance $* p<0.0001$. Data are expressed as mean of three replicates. 


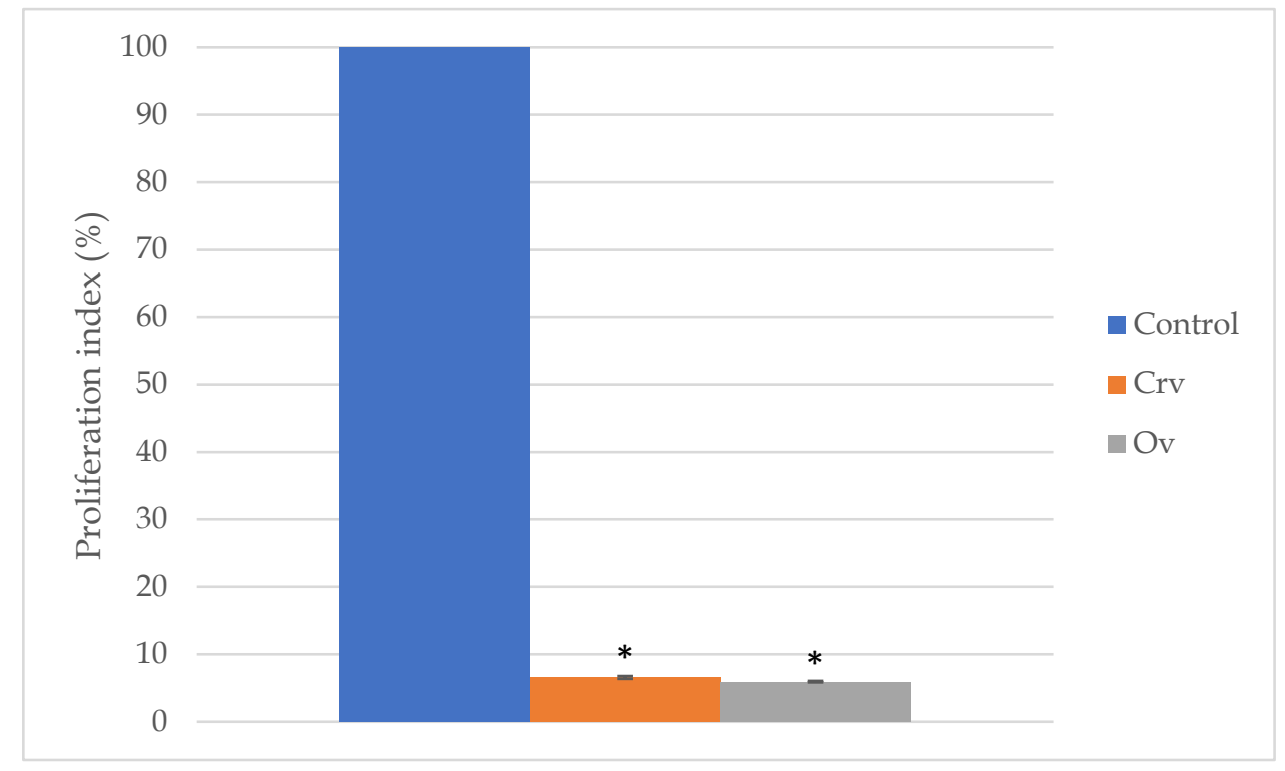

Figure 5. Graphic representation of the proliferation index of TN BC cells exposed to Ov infusion and Crv. Significance ${ }^{*} p<0.0001$ Data are expressed as mean of three replicates.

\section{Conclusions}

In conclusion, the present study provides insight into adjuvant treatments efficacy for the breast cancer, especially the $\mathrm{O} v$ infusion and $\mathrm{Crv}$ for treatment of aggressive BC subtypes like TN. Moreover, this information lay the groundwork so that in near future effective and economical adjuvant treatments can be promote, that are beneficial for the patient and society in different levels as patient health, individual and collective economy. Because $O v$ is a plant that is easily accessible to the general population. Furthermore, open the way for future studies that continue with a next investigation phase, with the aim of continue analyzing the efficacy of $O v$ infusion and Crv in this $\mathrm{BC}$ subtype, and in a last instance perform in vivo preclinical tests that shows the forcefulness of its use, with the sole purpose of evaluate the biosecurity of its use, to finally perform tests of its cytotoxic activity as adjuvant and support to the conventional treatments in patients with $\mathrm{TN}$ breast cancer.

Acknowledgments: The authors thank Universidad de Guadalajara for providing the facilities to carry out this study.

Conflicts of Interest: The authors declare no conflict of interest.

\section{References}

1. Hanahan, D.; Weinberg, R.A. Hallmarks of cancer: The next generation. Cell 2011, 144, 646-674, doi:10.1016/j.cell.2011.02.013.

2. GLOBOCAN. All Cancers. 2018. Available online: http://gco.iarc.fr/today (accessed on 26 February 2020).

3. GLOBOCAN. Breast. 2018. Available online: http://gco.iarc.fr/today (accessed on 26 February 2020).

4. Perou, C.M.; Sørile, T.; Eisen, M.B.; Van De Rijn, M.; Jeffrey, S.S.; Ress, C.A.; et al. Molecular portraits of human breast tumours. Nature 2000, 406, 747-752.

5. OMS. OMSINuevas Directrices de la OMS para Fomentar el uso Adecuado de las Medicinas Tradicionales. WHO. 2013. Available online: https://www.who.int/mediacentre/news/releases/2004/pr44/es/ (accessed on 26 February 2020).

6. Oniga, I.; Pușcaș, C.; Silaghi-Dumitrescu, R.; Olah, N.K.; Sevastre, B.; Marica, R.; Marcus, I.; SevastreBerghian, A.C.; Benedec, D.; Pop, C.E.; et al. Origanum vulgare ssp. vulgare: Chemical composition and biological studies. Molecules 2018, 23, 2077.

7. Sharifi-Rad, M.; Varoni, E.M.; Iriti, M.; Martorell, M.; Setzer, W.N.; del Mar Contreras, M.; Salehi, B.; SoltaniNejad, A.; Rajabi, S.; Tajbakhsh, M.; et al. Carvacrol and human health: A comprehensive review. Phyther. Res. 2018, 32, 1675-1687. 
8. OMS. OMSICáncer. Available online: https://www.who.int/topics/cancer/es/ (accessed on 26 February 2020).

9. ¿DC. ¿Qué es el cáncer de mama?/CDC. Available online: https://www.cdc.gov/spanish/cancer/breast/basic_info/what-is-breast-cancer.htm (accessed on 26 February 2020).

10. ACS. ¿Qué es el Cáncer de Seno?. Available online: https://www.cancer.org/es/cancer/cancer-deseno/acerca/que-es-el-cancer-de-seno.html (accessed on 26 February 2020).

11. Imigo, G.F.; Mansilla, S.E.; Delama, G.I.; Poblete, S.M.T.; Fonfach, Z.C. Clasificación molecular del cáncer de mama. CuadCir. 2011;25:67-74.

12. CDC. Cáncer de Mama Triple Negativo/CDC. Available online: https://www.cdc.gov/spanish/cancer/breast/triple-negative.htm (accessed on 26 February 2020).

13. Amin, A.R.M.R.; Kucuk, O.; Khuri, F.R.; Shin, D.M. Perspectives for cancer prevention with natural compounds. J Clin Oncol. 2009, 27, 2712-2725.

14. Reynoso-Noverón, N.; Mohar, A. El cáncer en México: Propuestas para su control. Salud Publica Mex. 2014, 56, S27-S32.

15. Fitzmaurice, C.; Dicker, D.; Pain, A.; Hamavid, H.; Moradi-Lakeh, M.M.M. The Global Burden of Cancer 2013. Jama Oncol. 2015, 1, 505-527.

16. Dias, D.A.; Urban, S.; Roessner, U. A Historical overview of natural products in drug discovery. Metabolites 2012, 2, 303-336.

17. Cordell, G.; Colvard, M. Natural products and traditional medicine. J. Nat. Prod. 2012, 75, 514-525.

18. Atanasov, A.G.; Waltenberger, B.; Pferschy-Wenzig, E.-M.; Linder, T.; Wawrosch, C.; Uhrin, P.; Temml V.; Wang, L.; Schwaiger, S.; Heiss E. Discovery and resupply of pharmacologically active plant- derived natural products: A review. Biotechnol. Adv. 2015, 33, 1-18.

19. Thomford, N.E.; Senthebane, D.A.; Rowe, A.; Munro, D.; Seele, P.; Maroyi, A.; Dzobo, K. Natural products for drug discovery in the 21st century: Innovations for novel drug discovery. Int. J. Mol. Sci. 2018, 19, 1578.

20. Khazir, J.; Mir, B.A.; Pilcher, L.; Riley, D.L. Role of plants in anticancer drug discovery. Phytochem Lett. 2014, 7, 173-181, doi:10.1016/j.phytol.2013.11.010.

21. Llana-Ruiz-Cabello, M.; Maisanaba, S.; Puerto, M.; Pichardo, S.; Jos, A.; Moyano, R.; Cameán, A.M. A subchronic 90-day oral toxicity study of Origanum vulgare essential oil in rats. Food Chem. Toxicol. 2017, $101,36-47$.

22. Elshafie, H.S.; Armentano, M.F.; Carmosino, M.; Bufo, S.A. Cytotoxic Activity of Origanum Vulgare L. on Hepatocellular Carcinoma cell Line HepG2 and Evaluation of its Biological Activity. Molecules 2017, 22, 1435.

23. Renukadevi, S.; Perumalsamy, H. Anti-proliferative activity of Origanum vulgare inhibited lipogenesis and induced mitochondrial mediated apoptosis in human stomach cancer cell lines. Biomed. Pharmacother. 2018, 108, 1835-1844, doi:10.1016/j.biopha.2018.10.028.

24. Dragoeva, A.P.; Koleva, V.P.; Nanova, Z.D. Allelopathy of Cold Water Extracts from Origanum vulgare ssp. vulgare L. Sci. Res. 2014, 3, 144-150.

25. Brđanin, S.; Bogdanović, N.; Kolundžić, M.; Milenković, M. Antimicrobial activity of oregano (Origanum vulgare L.) and basil (Ocimum basilicum L.) Extracts. Adv. Technol. 2015, 4, 5-10.

26. Zhang, X.; Guo, Y.; Wang, C.; Li, G.; Xu, J. Phenolic compounds from Origanum vulgare and their antioxidant and antiviral activities. Food Chem. 2014, 152, 300-306, doi:10.1016/j.foodchem.2013.11.153.

27. Gottumukkala Venkateswara Rao TMukhopadhyay TAnnamalai NRadhakrishnan, M.R.S. Chemical constituents and biological studies of Origanum vulgare Linn. Pharm. Res. 2011, 3, 143-146.

28. Criollo-mendoza, M.S.; Id, G.V.; Heredia, J.B. Flavonoids and Phenolic Acids from Oregano: Occurrence, Biological Activity and Health Benefits. Plants 2017, 7, 1-23.

29. Arigesavan, K.; Sudhandiran, G. Carvacrol exhibits anti-oxidant and anti-inflammatory effects against 1, 2-dimethyl hydrazine plus dextran sodium sulfate Induced inflammation associated carcinogenicity in the Colon of Fischer 344 rats. Biochem. Biophys. Res. Commun. 2015, doi:10.1016/j.bbrc.2015.04.030.

30. Mosmann, T. Rapid colorimetric assay for cellular growth and survival: Application to proliferation and cytotoxicity assays. J. Immunol. Methods 1983, 65, 55-63.

31. Khan, F.; Khan, I.; Farooqui, A.; Ansari, I.A. Carvacrol Induces Reactive Carvacrol Induces Reactive Oxygen Species (ROS)-mediated Apoptosis Along with Cell Cycle Arrest at G0/G1 in Human Prostate Cancer Cells. Nutr. Cancer 2017, 69, 1075-1087, doi:10.1080/01635581.2017.1359321. 
32. Han, X.; Parker, T.L. Anti-inflammatory, tissue remodeling, immunomodulatory, and anticancer activities of oregano (Origanum vulgare) essential oil in a human skin disease model. Biochim. Open 2017, 4, 73-77, doi:10.1016/j.biopen.2017.02.005.

33. Lim, W.; Ham, J. Carvacrol induces mitochondria-mediated apoptosis via disruption of calcium homeostasis in human choriocarcinoma cells. Cell Physiol. 2018, 1-13.

34. Khan, I.; Bahuguna, A.; Kumar, P.; Bajpai, V.K.; Kang, S.C. In vitro and in vivo antitumor potential of carvacrol nanoemulsion against human lung adenocarcinoma A549 cells via mitochondrial mediated apoptosis. Sci. Rep. 2018, 8, 712-714, doi:10.1038/s41598-017-18644-9.

35. Elbe, H.; Yigitturk, G.; Cavusoglu, T.; Baygar, T.; Ozgul Onal, M.; Ozturk, F. Comparison of ultrastructural changes and the anticarcinogenic effects of thymol and carvacrol on ovarian cancer cells: Which is more effective? Ultrastruct Pathol. 2020, 44, 193-202, doi:10.1080/01913123.2020.1740366.

36. Arunasree, K.M. Anti-proliferative effects of carvacrol on a human metastatic BCcell line, MDA-MB 231. Phytomedicine 2010, 17, 581-588, doi:10.1016/j.phymed.2009.12.008.

37. Vokou, D.; Kokkinit, S.; Bessiere, J. Geographic Variation of Greek Oregano (Origanum vulgare ssp. hirtum) Essential Oils. Biochem. Syst. Ecol. 1993, 21, 287-295.

38. Spyridopoulou, K.; Fitsiou, E.; Bouloukosta, E.; Tiptiri-Kourpeti, A.; Vamvakias, M.; Oreopoulou, A.; Papavassilopoulou, E.; Pappa, A.; Chlichlia, K. Extraction, Chemical Composition, and Anticancer Potential of Origanum onites L. Essential Oil. Molecules 2019, 24, 2612.

39. Makrane, H.; El Messaoudi, M.; Melhaoui, A.; El Mzibri, M.; Benbacer, L.; Aziz, M. Cytotoxicity of the Aqueous Extract and Organic Fractions from Origanum majorana on Human Breast Cell Line MDA-MB231 and Human Colon Cell Line HT-29. Adv. Pharm. Sci. 2018, 2018, 9.

40. Dhaheri YAl Attoub, S.; Arafat, K.; Abuqamar, S.; Viallet, J.; Saleh, A.; et al. Anti-Metastatic and Anti-Tumor Growth Effects of Origanum majorana on Highly Metastatic Human BCCells: Inhibition of NFкB Signaling and Reduction of Nitric Oxide Production. PLoS ONE 2013, 8, 1-17.

41. Cittera, A.; Cazzola, R.; Cestaro, B.; Precliniche, S. Antioxidant Properties of oregano (ohganum vulgare) leaf extracts. J. Food Biochem. 2000, 24, 453-465.

42. Dhaheri YAl Eid, A.; Abuqamar, S.; Attoub, S.; Khasawneh, M. Mitotic Arrest and Apoptosis in BCCells Induced by Origanummajorana Extract: Upregulation of TNF-a and Downregulation of Survivin and Mutant p53. PLoS ONE 2013, 8, 1-14.

Publisher's Note: MDPI stays neutral with regard to jurisdictional claims in published maps and institutional affiliations.

(C) 2020 by the authors. Submitted for possible open access publication under the terms and conditions of the Creative Commons Attribution (CC BY) license (http://creativecommons.org/licenses/by/4.0/). 